\title{
O INFLUXO DAS POLÍTICAS DE AVALIAÇÃO SOBRE O TRABALHO DOCENTE
}

\author{
The influence of the evaluation policies on teaching work
}

\author{
La influencia de las políticas de evaluación sobre el trabajo docente
}

\author{
Rogéria Moreira Rezende Isobe* \\ Valéria Moreira Rezende** \\ Lúcia de Fátima Valente ${ }^{* * *}$
}

\begin{abstract}
Resumo
O artigo apresenta resultados de investigação que analisa as percepções dos professores sobre as políticas de avaliação sistêmica e a incidência dessas avaliações nos currículos escolares. O estudo qualitativo foi realizado em uma escola estadual da rede pública de Minas Gerais que obteve baixo desempenho no Índice de Desenvolvimento da Educação Básica - Ideb. Os dados foram coletados por meio de entrevista semiestruturada realizada com docentes que atuam no $5^{\circ}$ ano do ensino fundamental. Os resultados corroboram a hipótese sobre os impactos negativos das avaliações sistêmicas no âmbito de uma política de resultados que restringe a autonomia da escola e do professor e submete a organização do currículo aos moldes de uma matriz de referência descontextualizada da realidade da escola.
\end{abstract}

PALAVRAS CHAVE: Trabalho docente. Avaliações sistêmicas. Políticas educacionais.

\begin{abstract}
The article presents the results of an investigation that analyzes the teacher's perceptions on the systemic evaluation policies and the influence of such evaluations on the school curriculum. The qualitative study was executed at a state school, part of the public schools system of the State of Minas Gerais, which obtained a low score on the Development Index of Basic Education - IDEB. The data was collected through semi structured interviews conducted with fifth grade teachers on elementary school. The results support the hypothesis of the negative impacts of the systemic evaluations lead within a result policy that restricts the autonomy of the school and of the teacher and subjugates the curriculum organization to a standard prototype decontextualized from the reality of the school.
\end{abstract}

KEYWORDS: Teaching work. Systemic assessments. Educational policies

\section{Resumen}

Este artículo presenta los resultados de investigación que analisa las percepciones de los profesores sobre las políticas de evaluación sistémica y la incidencia e esas evaluaciones en los currículos escolares. El estudio cualitativo fue realizado en una escuela estatal de la red pública del Estado de Minas Gerais que obtuvo bajo desempeño en el Índice de Desarrollo de la Educación Básica - IDEB. Los datos fueron

* Graduação em Pedagogia pela Universidade Federal de Uberlândia (2001), Mestrado (2004) e Doutorado (2008) em Educação pela Pontifícia Universidade Católica de São Paulo. Professora do Departamento de Educação da Universidade Federal do Triângulo Mineiro (UFTM). E-mail: rogeriaisobe@gmail.com

** Doutora em Educação pela Pontifícia Universidade Católica de São Paulo. Professora Associada da Universidade Federal de Uberlândia - UFU. Atualmente é docente pesquisadora do Curso de Pedagogia da Universidade Federal de Uberlândia - FACIP. E-mail: valeria.rezende@ufu.br

*** Graduada em Pedagogia e Direito pela Fundação Educacional do Nordeste Mineiro - Fenord (1991 - 1997), especialista em Ética e Filosofia Política pela Universidade Federal de Uberlândia (1999), mestre e doutora em educação pela mesma universidade (2002-2011). É professora da Universidade Federal de Uberlândia, no Campus do Pontal. E-mail: valentelucia@ufu.br 
recolectados por medio de una entrevista semiestructurada realizada con docentes que actúan en el $5^{\circ}$ año de la enseñanza básica. Los resultados corroboran la hipótesis sobre los impactos negativos de las evaluaciones sistémicas en el marco de una política de resultados que restringe la autonomía de la escuela y del profesor y somete la organización del currículo a los moldes de una matriz de referencia descontextualizada de la realidad de la escuela.

PALABRAS CLAVE: Trabajo docente. Evaluaciones sistémicas. Políticas educativas.

\section{INTRODUÇÃO}

O impacto das reformas educacionais ocorridas na década de 1990 sobre a organização curricular e o sistema de avaliação tem sido objeto de vasta literatura especializada - artigos científicos, livros e teses acadêmicas - que analisam o amálgama resultante daquelas reformas sob distintas perspectivas e teorizações. As ingerências da política de responsabilização da escola e do professor sobre o desempenho escolar dos estudantes, os mecanismos de controle e monitoramento do trabalho docente, os recorrentes resultados de fracasso no desempenho das avaliações em larga escala, a introdução da lógica de mercado e com ela a imposição da política de resultados, os princípios de meritocracia e competitividade, a adoção de critérios de bonificação como estratégia de estímulo às escolas e professores de sucesso. Esses são alguns problemas enfatizados por Casassus (2009) Freitas (2005, 2006, 2014), Hypólito (2010), Ball (2001), Bonamino e Souza (2012), entre outros.

No âmbito daquela governamentalidade neoliberal iniciada na década de 1990, proclamada como Nova Gestão Pública (NGP), ocorre um gradativo processo de privatização de serviços públicos com a implementação da racionalidade econômica e mercadológica na oferta de bens e serviços essenciais, entre eles a educação (OLIVEIRA, 2015). Essa forma de gestão preconizada pela NGP caracteriza-se pela adoção dos critérios da economia privada na administração estatal configurando-se como estratégia governamental de desresponsabilização das políticas públicas, numa clara intenção de minimização dos direitos sociais. Nesse processo, educação é concebida como mercadoria e o ensino como forma de comércio (DOURADO, 2002).

Ao mesmo tempo em que se desresponsabiliza o estado aumenta as estratégias de controle, utilizando como mecanismos regulatórios a elaboração de indicadores de desempenho e avaliação de resultados com incentivo a competitividade entre as instituições escolares circunscrevendo, desta forma, a atuação dos sujeitos escolares à racionalidade mercantil.

Em decorrência da incorporação das orientações da NGP na área da educação, o ambiente escolar é, pois, invadido pelo que Afonso (2014) denomina de "avaliocracia" que consiste na configuração de um campo saturado de avaliações: dos alunos, dos professores, das escolas, dos sistemas de ensino, dos projetos, dos programas e das próprias políticas educacionais. Pressionados por esse novo modo de regulação pautado na exacerbação da competitividade e obrigação de resultados, os professores centralizaram suas ações nos programas de ensino pautados nos indicadores de desempenho das avaliações sistêmicas, alvo da política de controle governamental.

Com o objetivo de contribuir para o debate sobre a temática em tela este trabalho analisa as percepções dos professores sobre as políticas de avaliação sistêmica e a incidência dessas avaliações nos currículos escolares. A investigação consiste em um estudo de caso sobre uma escola estadual da rede pública de Minas Gerais que obteve baixo desempenho no Índice de Desenvolvimento da Educação Básica - Ideb. O material empírico analisado nesta pesquisa, de 
natureza qualitativa, consiste em um conjunto de documentos referente aos resultados da escola na Prova Brasil de 2009 a 2013, disponíveis na internet, assim como os dados obtidos por meio de entrevistas semiestruturadas com professoras que atuam com alunos $5^{\circ}$ ano do ensino fundamental e estão, portanto, submetidos à avaliação da Prova Brasil, obrigatória para o cálculo Ideb.

$\mathrm{Na}$ apresentação deste trabalho serão discutidas primeiramente questões referentes ao trabalho docente. Na sequência, abordará a centralidade das avaliações na política de regulação da educação e serão apresentados os resultados da pesquisa analisando os meandros das políticas de avaliação e do currículo no cotidiano das escolas. Ao final serão tecidas algumas considerações na perspectiva contribuir para as reflexões sobre o caráter controlador das avaliações sistêmicas e seu impacto sobre o currículo escolar.

\section{O trabalho docente no contexto das reformas educacionais}

As mudanças que vêm sendo operadas no trabalho docente estão diretamente ligadas às metamorfoses do mundo do trabalho e dando respostas ao processo de reformas, regulações e regulamentações educacionais implementados, nas duas últimas décadas do século passado e início desse novo século. Assim como o mundo do trabalho, de acordo com Duarte (2006), o processo de trabalho docente é marcado por tensões, contraposições, contradições, indeterminações e resistências.

Estudos realizados por Novaes (1984) no final da década de 1970 e início de 1980, já apontavam para a precarização do trabalho docente, o desprestígio do magistério, a desvalorização manifestada pelos baixos salários e as características socioeconômicas dos docentes. A autora analisou as mudanças substanciais nos processos de trabalho do professor por meio da adequação do modelo fabril à escola com a implantação da lógica da especialização e segmentação, ou seja, a separação da concepção da execução do trabalho. Nesse contexto, a correção das distorções se dava por meio do controle da autonomia pessoal no campo educativo, controle esse exercido à época pela figura do inspetor escolar.

Oliveira (2004) ao pesquisar as condições de trabalho dos docentes no Brasil constatou um processo de reestruturação do trabalho pedagógico. As mudanças traduzidas por meio das reformas educacionais mais recentes têm resultado na intensificação do trabalho docente, na ampliação de suas atividades que extrapolam o processo de ensinar/aprender e que tem como consequência o desgaste e a insatisfação dos trabalhadores.

Com efeito, o fato de o trabalho pedagógico ter sido reestruturado sem as adequações necessárias, ou seja, sem condições objetivas de trabalho e salários dignos, levou à precarização do trabalho docente e a consequente desqualificação profissional, bem como a perda do sentido do trabalho. Essa situação está relacionada com as transformações do mundo contemporâneo e com reformas educacionais implementadas no Brasil nas duas últimas décadas.

Lourencetti (2006) em seus estudos sobre a intensificação do trabalho docente, investiga como esse processo se concretiza no cotidiano escolar e conclui que os professores estão sobrecarregados e insatisfeitos, sobretudo pelo excesso de responsabilização e perda da especificidade do ofício de ensinar, na medida em que os professores deparam com situações problemáticas múltiplas na sala de aula, que de certa forma extrapolam a mediação do processo ensino aprendizagem.

Evidencia assim, como postula Shiroma e Noronha (2004), um descompasso entre a ampliação das atividades docentes e a redução do espectro político da profissão. Ao mesmo 
tempo em que os profissionais são cobrados por competências que extrapolam a sala de aula, o professor deve focalizar os resultados do seu ensino com base nas diretrizes propostas, sem as condições objetivas de trabalho que possibilitem uma análise mais aprofundada da realidade e lhes permita assumir outras atribuições.

Nessa lógica, os docentes são tomados como consumidores das reformas, muitas vezes assumidas irrefletidamente, abstraindo-se das condições políticas que as produzem. São compelidos a buscar a eficiência e mostrar os resultados, independente dos processos que têm vivenciado. Problemas relacionados à extensa e intensa carga horária, ao número elevado de alunos por turma, recursos didáticos desatualizados, ausência de condições objetivas para o planejamento e execução do trabalho docente, instabilidade do corpo docente e técnico das escolas, a rotatividade, o absenteísmo, os baixos salários, as jornadas duplas e triplas, às diferentes formas de contratos, caracterizados como efetivo, temporário e precarizado, ao adoecimento causado pelo desgaste físico e emocional que afeta a qualidade de vida e à saúde. Acrescentando a tudo isso, uma política salarial que apresenta uma grande diversidade e que compromete o desempenho de um bom trabalho.

Outra dimensão importante a ser considerada no trabalho docente refere-se à autonomia. Ao mesmo tempo em que a legislação garante a autonomia das escolas e do professor, há um controle sistemático, um monitoramento por meio das avaliações que atualmente tem se caracterizado pela responsabilização do profissional perante o fracasso do aluno e pela falta de qualidade do ensino (OLIVEIRA, 2004; 2005; 2007).

Uma consequência direta da separação entre concepção e execução do trabalho educacional, está relacionada ao sentimento de impotência por parte dos professores pois a perda do controle do próprio trabalho gera o desânimo, uma vez que a autonomia lhes é retirada. Percebe-se aí o retorno à concepção tecnicista de educação, revestida de novas tecnologias e processos definidos por Freitas (2011) de neotecnicismo.

Santos (2004) ao analisar as repercussões das novas políticas públicas no campo educacional, sobretudo no que se refere ao trabalho docente, constatou que tais políticas influenciam o desenvolvimento da cultura do desempenho em que a performance é a principal referência do Estado avaliador. Em consequência disso, se configuram novas facetas nas relações entre os profissionais do ensino, seu trabalho e sua identidade profissional. Nessa perspectiva, os resultados da avaliação passam a ser o foco do trabalho docente, da direção da escola e dos órgãos superiores de educação. Outras atividades que compõem o processo de formação dos educandos, num sentido mais amplo, são relegados.

Essa cultura da performatividade gera nos professores uma atitude de auto culpabilização pelos problemas da escola, dos alunos, do seu trabalho. Essa situação tem como consequências o desgaste emocional e um sentimento de impotência por não ter conseguido realizar aquilo que foi imposto. É evidente que os professores são responsáveis pelo desenvolvimento da aprendizagem dos alunos, no entanto a maior parte dos problemas que enfrenta nesse campo está relacionado aos aspectos econômicos, sociais e institucionais e não apenas ao seu trabalho pessoal.

Com efeito, os processos de avaliação sistêmica têm direcionado a organização pedagógica da escola e o trabalho docente. A cultura do desempenho, da performatividade somadas à lógica da responsabilização e da culpabilização diante dos resultados dos índices implantados, entre outros fatores, tem afetado sobremaneira o trabalho docente.

\section{A centralidade das avalições sistêmicas nas políticas de regulação do ensino}


O sistema de aferição por meio de avaliações tem sido, desde a década de 1990, ponto de pauta cada vez mais proeminente no âmbito das políticas educacionais, em consonância com o que vem acontecendo em outros países como mostra os estudos desenvolvidos por Bonamino e Souza (2012); Afonso (2009, 2012); Ball (2004, 2005); Casassus (2009); Freitas (2012), entre outros.

As avaliações sistêmicas, também denominadas externas, consistem na aplicação de testes padronizados em larga escala com o objetivo de aferir conhecimentos e estabelecer um diagnóstico da aprendizagem do aluno a partir do nível de escolaridade em que ele se encontra. No Brasil, todos os níveis de ensino, exceto a educação infantil, são submetidos aos testes da avaliação sistêmica, organizada e centralizada pelo Instituto Nacional de Estudos e Pesquisas Educacionais Anísio Teixeira (Inep) órgão ligado ao Ministério da Educação e Cultura (MEC). É um instrumento, portanto, elaborado por agentes que não fazem parte do cotidiano da escola.

O rol de avaliações organizado pelo Sistema Nacional de Avaliação da Educação Básica (Saeb) tem a seguinte configuração: a Avaliação Nacional da Educação Básica (ANEB) de aplicação amostral e de realização bianual destina-se aos alunos do $5^{\circ}$ e $9^{\circ}$ ano do ensino fundamental e $3^{\circ}$ ano do ensino médio da rede pública e privada, nas zonas urbana e rural; Avaliação Nacional do Rendimento Escolar (ANRESC) também denominada Prova Brasil, que também é censitária e de realização bianual destina-se aos alunos do $5^{\circ}$ e $9^{\circ}$ ano do Ensino Fundamental. A Prova Brasil passou a fazer parte do Saeb em 2007. Avaliação Nacional da Alfabetização (ANA), incorporada ao sistema em 2013, é censitária e de realização anual, para os alunos do $3^{\circ}$ ano do ensino fundamental; os instrumentos de avaliação compreendem um conjunto de questões cognitivas que são aplicadas para os alunos e também um questionário contextual a ser respondido pelos estudantes, professores e direção da escola.

O destaque premente nos resultados do Saeb é o Índice de Desenvolvimento da Educação Básica (Ideb) que é calculado por meio de uma fórmula baseada em indicadores do fluxo escolar, obtidos através do censo escolar e desempenho dos estudantes nas avaliações externas. Esse índice culmina no estabelecimento de uma nota que se configura em parâmetro balizador de metas a serem atingidas com o propósito de alcançar uma pretensa qualidade educacional traduzida em competências e habilidades.

De acordo com os estudos de Afonso (2014), Souza e Oliveira (2003), Freitas (2006) e Ball (2001), como arauto da qualidade educacional, o Ideb funciona como um dispositivo de quase mercado educacional na medida em que, após a divulgação de seus dados pela mídia e pelos órgãos oficiais, são elaborados rankings das melhores escolas e também das piores escolas do Brasil, sem levar em conta as imensas diferenças regionais, socioeconômicas e culturais que permeiam as práticas escolares. Cria-se, com isso, um ethos competitivo no sistema de ensino, baseado na racionalidade neoliberal cuja tônica reside na lógica do mercado.

Essa política de accountability ${ }^{l}$ resulta em prêmios e punições para docentes e escolas em um processo que vincula, inclusive, o financiamento da educação, na medida há uma destinação de parcela extra de recursos do Programa Dinheiro Direto na Escola (PDDE) para os estabelecimentos de ensino que atingirem a meta estabelecida pelo Ideb, definindo, desta forma, os destinos das escolas, que ora se saem exitosas, ora remediadas pela "bacia das almas".

\footnotetext{
${ }^{1}$ Afonso (2012, p. 472) define o termo accountability como uma "forma hierárquico-burocrática ou tecnocrática e gerencialista de prestação de contas que, pelo menos implicitamente, contém e dá ênfase a consequências ou imputações negativas e estigmatizantes, as quais, não raras vezes, consubstanciam formas autoritárias de responsabilização das instituições, organizações e indivíduos”.
} 
Os estudos de Bonamino e Souza (2012) e Hypólito (2010) analisam os dispositivos de bonificação para os profissionais da educação que, por sua vez, obtêm um ganho financeiro adicional condicionado à nota obtida no Ideb. Hypólito (2010) esclarece o quão perversa é esta política de bonificação que estimula a competitividade entre os professores, aumenta a pressão emocional gerada pelo excesso de trabalho, restringe o convívio social que dá lugar a prática isoladas, além de gerar o "efeito do terror" nos professores em decorrência da neurose da accountability.

A tendência é de que ocorra uma competição desenfreada pelo bom desempenho, como se fora uma competição para quem ganha mais no mercado. A possibilidade de um trabalho coletivo, que tenha como critério o entorno escolar e os profissionais envolvidos, fica comprometida pelo imperioso alcance de metas (HYPÓLITO, 2010, p. 1348).

É preciso considerar, entretanto, que não existem provas contundentes de que o sistema de bonificação de professores tenha um efeito expressivo sobre a qualidade do processo de ensino-aprendizagem e o desempenho dos alunos, sobretudo quando se agrega conhecimento significativo e não apenas uma resposta numérica. Além disso, não são consideradas outras variáveis quando se pretende medir o impacto do trabalho docente no desempenho dos alunos, como: remuneração, plano de carreira, número de alunos atendidos, carga horária, condições de trabalho, entre outros.

Sob os ditames do Estado Avaliador (AFONSO, 1999) a qualidade de ensino passou a ser medida pelas notas e pelos resultados obtidos por meio das avaliações externas, que subsidiam, desta forma, a tomada de decisões da gestão escolar. Frente a uma nova governabilidade da educação e a um conceito de qualidade consubstanciado no Ideb, a educação caminha na contramão do que se espera da formação integral do sujeito.

O Plano Nacional de Educação (PNE) estabelece uma escala de progressão do Ideb para que todas as escolas alcancem a media 6 até 2022, ano que encerra a vigência do PNE. As escolas, submetidas aos ditames desse ordenamento ficam em estado de "alerta" e são compelidas a priorizar os conteúdos expressos nas matrizes de referência ${ }^{2}$, que estabelecem, por sua vez, as habilidades a serem alcançadas pelos alunos nos anos escolares submetidos ao processo de avaliação externa. São essas matrizes de referência que determinam o que deve ser ensinado e não o currículo definido pela Base Nacional Comum (VIEIRA e BRAGA, 2012).

$\mathrm{Na}$ articulação entre currículo e avalição nota-se, pois, certa ambiguidade nas escolas brasileiras. De um lado, as prescrições registram a importância da abordagem interdisciplinar e da valorização da diversidade cultural na educação básica. Por outro lado, a organização curricular tem sido conduzida cada vez mais pelas avaliações sistêmicas que priorizam os conhecimentos relacionados às disciplinas de Língua Portuguesa e Matemática. Cabe registrar aqui as análises de Barreto (2012, p. 746):

O que parece estar se tornando mais frequente nas redes escolares é a prescrição do quê, como e quando deve ser ensinado e, inclusive, do como deve ser avaliado, incitando os professores à conformidade às regras de trabalho, restringindo-lhes a autonomia no trato com os conteúdos escolares e estabelecendo o controle sobre as suas práticas. Não é raro que a prescrição do que deve ser ensinado, ou, dizendo de outro modo, do que se espera que o aluno aprenda, tenda, por sua vez, a reduzir-se, ela mesma, a uma matriz de avaliação que termina por tomar o lugar do currículo.

\footnotetext{
${ }^{2}$ No site do Inep consta a finalidade da matriz de referência e dos descritores. Cf. http://www.inep.gov.br)
} 
$\mathrm{Na}$ busca obstinada por melhores resultados nos rankings nacionais e internacionais, os professores passam a ter como foco a chamada "examocracia", ou seja, a reificação da cultura de exames, na qual todas as atividades escolares perdem o caráter formativo e se voltam para o treinamento programado com o intuito de "resolver provas", a partir de uma sequência de conteúdos trabalhados de forma fragmentada e descontextualizada.

\section{Com a palavra, as professoras da escola reprovada}

Com o objetivo de contribuir para o debate sobre os mecanismos de avalição sistêmica frente a uma nova governabilidade da educação pública realizou-se, conforme mencionado, uma pesquisa referente a percepção de docentes sobre aquele tipo de avaliação e sua incidência no trabalho docente. A coleta de dados foi feita por meio de entrevistas semiestruturadas com quatro professoras que lecionam no $5^{\circ}$ ano de uma escola estadual da rede pública de Minas Gerais que oferece os anos iniciais do Ensino Fundamental nos períodos matutino e vespertino.

A tabela a seguir apresenta os dados da escola analisada - aqui denominada "Alfa" nas avaliações da Prova Brasil correspondente aos anos de 2009, 2011 e 2013:

\section{Tabela1}

Resultados da proficiência da escola Alfa (2009-2013)

\begin{tabular}{|c|c|c|c|c|c|}
\hline Ano & $\begin{array}{c}\text { Proficiência } \\
\text { em } \\
\text { português }\end{array}$ & $\begin{array}{l}\text { Proficiência } \\
\text { em } \\
\text { Matemática }\end{array}$ & $\begin{array}{c}\text { Índice } \\
\text { do } \\
\text { Ideb }\end{array}$ & $\begin{array}{l}\text { Meta a ser } \\
\text { alcançada }\end{array}$ & $\begin{array}{l}\text { Resultado } \\
\text { da escola }\end{array}$ \\
\hline 2009 & $46 \%$ & $46 \%$ & 5,6 & 5,1 & PRECISA MELHORAR \\
\hline 2011 & $38 \%$ & $35 \%$ & 5,3 & 5,5 & REPROVADA \\
\hline 2013 & $43 \%$ & $31 \%$ & 5,3 & 5,7 & REPROVADA \\
\hline
\end{tabular}

Fonte: Tabela elaborada pelas autoras com base nos dados disponíveis no site do Inep.

Os dados demonstram o baixo desempenho da escola Alfa entre os anos de 2009 a 2013 na medida em que não atingiu 50\% de proficiência nas disciplinas avaliadas. Em Português houve uma queda de 2009 para 2011, retomando com uma sutil ascensão em 2013. Em matemática houve uma queda progressiva nas avaliações, chegando a um terço da média estipulada. As duas últimas avaliações a que a escola Alfa foi submetida estão representadas pela cor vermelha. Isso significa que a instituição não atingiu os resultados no Ideb e foi reprovada.

Cabe salientar que a Prova Brasil, de aplicação censitária e bianual, abarca questões de Língua Portuguesa - com ênfase na leitura e de Matemática cujo foco centraliza-se na resolução de problemas. Esses conteúdos seguem uma matriz de referência que são tópicos descritivos das competências e habilidades que os alunos supostamente deveriam saber nos anos escolares avaliados.

Interrogadas sobre os processos de avaliação externa, os resultados obtidos pela escola e a organização curricular todas as professoras entrevistadas alegaram sofrer forte pressão da 
equipe pedagógica da escola para o trabalho exclusivo dos conteúdos prescritos nas matrizes de referência que conduzem, por sua vez, à elaboração da Prova Brasil. Na busca obstinada por melhores resultados, os gestores escolares estabelecem certo policiamento pedagógico na escola conforme relata a professora: "a supervisora fica passando pelas salas e observando o que está sendo aplicado no quadro e se a gente tá ou não trabalhando o conteúdo certo" (Entrevista concedida pela professora P3). O depoimento de outra docente também demonstra essa questão:

\begin{abstract}
A gente trabalha o tempo todo sob pressão [...] eles não consideram o fator emocional das crianças e nem da gente trabalhando sob pressão. Só querem cobrar que todo mundo esteja no básico ou suficiente. Mas você não chega na sala e vai jogando, despejando simplesmente o conteúdo né? Não é assim que funciona. A gente tá lidando com pessoas e também a realidade dentro da sala de aula é outra (Entrevista concedida pela professora $\mathrm{P} 4)$.
\end{abstract}

Sob a égide das chamadas políticas de responsabilização - cujo objetivo é culpabilizar os gestores e docentes pelos resultados de suas escolas, desresponsabilizando assim, o Estado - os profissionais que trabalham na escola centralizaram suas ações nas matrizes curriculares pautadas nos indicadores de desempenho das avaliações sistêmicas. O impacto dessas avalições no currículo está expresso de modo fidedigno na fala de outra professora:

\begin{abstract}
A minha prática pedagógica está bem alinhada, aliás, ela já é feita a partir da matriz curricular. Eu já começo o ano com a matriz na mão. Aí a gente passa a ter um trabalho em cima das habilidades da matriz de referência da prova. Não é que eu esqueço os direitos de formação geral dos alunos, eu até sei disso, mas aqui não temos espaço para isso. O negócio é seguir a matriz curricular e agrega-la nas aulas. Isso vai me dar a certeza que estou no caminho que eles querem que eu percorra (Entrevista concedida pela professora $\mathrm{P} 4)$.
\end{abstract}

As avaliações externas corroboram a lógica do controle nas diversas instâncias do sistema de ensino com repercussões sobre os currículos e o trabalho docente restringindo a autonomia dos sujeitos escolares sobre o que ensinar, como e quando ensinar em conformidade as expectativas de aprendizagens medidas em testes padronizados. Os problemas decorrentes da forma de implementação do sistema de avaliações sistêmicas atingem também muitos alunos que assolados pelo medo do fracasso, sofrem com bloqueios advindos de uma ansiedade extrema no momento da prova como elucida o relato da docente:

Eu tenho um aluno que tem fobia de prova e na última do Estado ele chorou muito e chegou a fazer xixi na roupa de nervoso. Acabou que entregou a prova em branco. E fora das avaliações ele é um aluno bom, faz as tarefas direitinho, mas na hora da prova ele entra em pânico. A pressão é muito grande né? Nem adulto resiste quanto mais uma criança. (Entrevista concedida pela professora P3)

O efeito perverso da lógica meritocrática consiste na estigmatização de docentes e discentes uma vez que o bom ou mau desempenho é relacionado com as "aptidões" de cada um condicionando, desta forma, o resultado obtido ao esforço e mérito de cada estudante, professor e, consequentemente da escola. Assim fica o Estado isento de responsabilidade e reforça, ao mesmo tempo, o processo de exclusão quando transfere a culpa para os sujeitos escolares. No entanto há questionamentos sobre a submissão do currículo aos ditames das avaliações padronizadas conforme depoimento de uma professora: 
Se o professor não tentar fazer diferente vai acabar trabalhando igualzinho eles mandam. O Estado já manda tudo pronto e o professor nem tem que pensar né? Muitos professores pegam o roteiro e não sai disso [...] só português e matemática. E a realidade do aluno? E o que ele realmente precisa? É só português e matemática que conta? E o que não consegue aprender? Tem muita coisa que a gente nem sabe o porquê está ali, mas está. E tem que ensinar pra conseguir nota boa na prova né? Acaba que o trabalho do professor fica distante da realidade do aluno (Entrevista concedida pela professora $\mathrm{P} 2$ ).

Na perspectiva da professora esse tipo de avaliação prioriza os aspectos cognitivos do currículo - relacionados especificamente aos de língua portuguesa e matemática descaracterizando outros fatores igualmente importantes para a formação integral do sujeito, mas que não é contabilizado para as políticas que valorizam resultados.

Uma questão destacada pelas professoras entrevistadas refere-se ao fato de que os testes estandardizados estabelecem um padrão a ser seguido no currículo e a abordagem homogeneizadora do ensino passa a ser fator imprescindível no êxito ou fracasso dos resultados. Esse processo configura-se em um entrave no ensino de acordo com a depoente: “[...] trabalho numa sala com 36 alunos e cada um tem seu tempo para aprender [...] tenho aluno que ainda não consegue nem ler e escrever direito. Como é que eu vou exigir o que o estado exige dele?" (Entrevista concedida pela professora P1).

Outra entrevistada destaca o contrassenso na aposta em exames padronizados justamente quando as questões relacionadas à diversidade cultural estão sendo debatidas no cenário educacional brasileiro: "[...] tem tanta coisa importante pra ensinar pra esses meninos, mas a gente tem que ficar preso no que o estado vai cobrar. Isso não tá certo né? Onde fica a diversidade que eles tanto falam pra gente trabalhar? [...]" (Entrevista concedida pela professora P2).

Quando as instâncias de governo adotam o sistema de avaliação em larga escala como fundamento de suas políticas educacionais, tem como premissa uma suposta igualdade de condições, conforme descrito, sem nenhum pudor, no documento oficial: "como o direito ao aprendizado de competências cognitivas vale para todos os alunos, fica excluída a possibilidade de definição deste direito de forma diferente para diferentes grupos de alunos [...] como consequência, o instrumento verificador do direito tem de ser o mesmo" (BRASIL, 2008, p. 7).

O propalado discurso da meritocracia desconsidera, pois, a interdependência de variáveis que se entrelaçam na configuração de uma qualidade educacional, tais como nível socioeconômico e cultural dos alunos; formação docente; valorização do magistério; infraestrutura da escola; condições materiais; gestão escolar, entre outros. Freitas (2012, p 383) apresenta uma dura crítica essa suposta igualdade de oportunidades:

\footnotetext{
A meritocracia é uma categoria, portanto, que perpassa a responsabilização. Ela esta na base da proposta política liberal: igualdade de oportunidades e não de resultados. Para ela, dadas as oportunidades, o que faz a diferença entre as pessoas e o esforço pessoal, o mérito de cada um. Nada é dito sobre a igualdade de condições no ponto de partida. No caso da escola, diferenças sociais são transmutadas em diferenças de desempenho e o que passa a ser discutido é se a escola teve equidade ou não, se conseguiu ou não corrigir as "distorções" de origem, e esta discussão tira de foco a questão da própria desigualdade social, base da construção da desigualdade de resultados.
} 
Diante desse impasse: de um lado o imperativo do conteúdo moldado pelas avaliações sistêmicas e de outro lado as reais necessidades de aprendizagem dos alunos os sujeitos escolares vivenciam sentimentos de frustração, impotência e auto responsabilização pelos resultados dos alunos e do estabelecimento de ensino, como elucida o depoimento da professora:

[...] a gente acaba tendo culpa também né? Porque a gente faz parte do sistema. Bem ou mal o que o aluno aprende ou deixa de aprender passa pelos professores [...] se o aluno se sai bem na prova [Prova Brasil] a gente se sente recompensada, mas se sai mal a gente fracassa junto com ele né?[...] a gente quer fazer o certo, mas parece que não alcança nunca [...] Sempre que tem algum curso bom eu pago uma substituta tanto no período da manhã como da tarde pra eu poder participar [...] porque a gente tem que capacitar né? (Entrevista concedida pela professora P2).

Freitas (2012) adverte sobre o impacto das políticas de responsabilização na chamada "corrida para o centro" que consiste na ação dos professores em priorizar os alunos que se encontram na média dos padrões de desempenho prejudicando, desta forma, os extremos da curva, ou seja, tanto os alunos de mais alto desempenho como os de pior desempenho. Esse problema torna-se visível no relato de uma professora: “[...] eu e outras professoras já tivemos que buscar menino em casa pra fazer a prova porque é bom aluno [...] e com muito jeitinho dispensamos os alunos mais fracos [...] mas tem mãe que manda o menino assim mesmo [...]" (Entrevista concedida pela professora P4).

Fica evidente que a construção de uma escola de qualidade não significa apresentar resultados exitosos nos índices da avaliação externa, mesmo porque esses resultados podem ser fraudados. Uma escola de qualidade requer a capacidade de produzir conhecimentos transformadores para que os alunos desenvolvam o pensamento crítico e construam noções de cidadania.

\section{CONSIDERAÇÕES FINAIS}

A investigação realizada corrobora a hipótese sobre os impactos negativos das avaliações sistêmicas no âmbito de uma política de resultados que restringe a autonomia da escola, cerceia o trabalho do professor e submete a organização do currículo aos moldes de uma matriz de referência descontextualizada da realidade da escola.

Ao discorrerem sobre as avaliações externas, as docentes entrevistadas revelam, majoritariamente, sentimentos de apreensão, culpa, despreparo e sensação de ser alvo de ações de vigilância e controle no âmbito escolar. Não se posicionaram explicitamente contra os processos de avaliação sistêmica, mas teceram críticas sobre a política de resultados cuja tônica reside nos testes estandardizados que acabam determinando fortemente o currículo escolar. Em decorrência, há uma redução expressiva da autonomia do professor na produção de saberes significativos na escola.

Consternadas por pressões de gestores da escola e pelo próprio sistema de prêmios e punições as docentes revelaram dilemas relativos à sua autonomia: por um lado são compelidas a atender as demandas ditatoriais das avaliações sistêmicas que engessam o currículo e determinam o seu fazer, de outro lado sentem-se impelidas a trabalhar como acreditam ser melhor para atender às necessidades e interesses de seus alunos. 
Envasadas no gerencialismo e pela onipresente linguagem de mercado, as políticas educacionais brasileiras, não priorizam a intervenção nas questões estruturais para resolver as mazelas da educação brasileira. Na contramão dessa lógica mercadológica, é preciso ampliar as discussões sobre o conceito de qualidade e as condições do trabalho docente desenvolvendo mecanismos que compreendam uma sistemática da avaliação como ferramenta capaz de contribuir na construção de um currículo vivo, ancorado na realidade e voltado para a transformação social. Esse é o verdadeiro sentido da avaliação e do currículo que ainda está longe de ser praticado nas escolas.

\section{REFERÊNCIAS}

AFONSO, A. J. Estado, Mercado, Comunidade e Avaliação: Esboço para uma rearticulação crítica. Educ. Soc., ano XX, nº 69, p. 139-164, Dezembro/99.

AFONSO, A. J. Avaliação educacional: Regulação e emancipação: Para uma sociologia das políticas avaliativas contemporâneas. São Paulo: Cortez, 2009.

AFONSO, A. J. Para uma conceitualização alternativa de accountability em educação. Educ. Soc.,

Campinas, v. 33, n. 119, p. 471-484, abr.-jun. 2012.

AFONSO, A. J. Questões, objetos e perspectivas de Avaliação. Avaliação, Campinas; Sorocaba, SP, v. 19, n. 2, p. 487-507, jul. 2014.

BALL, S. J. Diretrizes Políticas Globais e Relações Políticas Locais em Educação. Currículo sem Fronteiras, v.1, n.2, pp.99-116, Jul/Dez 2001.

BALL, S. J. Performatividade, Privatização e pós-Estado de Bem-Estar. Educ. Soc. v. 25 n. 89 Campinas set./dez. 2004.

BALL, S. J. Profissionalismo, gerencialismo e performatividade. Tradução de Celina Rabelo Duarte; Maria Lúcia Mendes Gomes; Vera Luiza Macedo Visockis. Cadernos de Pesquisa, São Paulo, v. 35, n. 126, p. 539-564, set./dez. 2005.

BONAMINO. A e SOUZA, S. Z. Três gerações de avaliação da educação básica no Brasil: interfaces com o currículo da/na escola. Educação e Pesquisa, São Paulo, p. 1-16, fev., 2012.

CASASSUS, J. Uma nota crítica sobre a avaliação estandardizada: a perda da qualidade e a segmentação social. Sísifo. Revista de Ciência da Educação, pp71-78, 2009. 
DOURADO, L. F. Reforma do estado e as políticas para a educação superior no Brasil nos anos 90. Educ. Soc., Campinas, vol. 23, n. 80, setembro/2002, p. 234-252.

DUARTE, Adriana Maria C. O processo de trabalho docente na educação básica: a análise dos pesquisadores da Rede Estrado. Revista de C. Humanas, Vol. 6, No 2, p. 239-252, Jul./Dez. 2006.

FREITAS, L.C. Qualidade negociada: avaliação e contrarregulação na escola pública. Educ. Soc, Campinas, v. 26, n. 92, p. 911-933, 2005.

FREITAS, L.C. Responsabilização, meritocracia e privatização: conseguiremos escapar ao neotecnicismo? In: Anais do Congresso Brasileiro de Educação. CBE, CEDES: Campinas, 2011.

FREITAS, L.C. Crítica da organização do trabalho pedagógico e da didática. Campinas: Papirus, 8 a edição, 2006.

FREITAS, L.C. Os reformadores empresariais da educação: da desmoralização do magistério à destruição do sistema público de educação. Educ. Soc., Campinas, v. 33, n. 119, p. 379-404, abr.-jun. 2012.

FREITAS, L.C. Os reformadores empresariais da educação e a disputa pelo controle do processo pedagógico na escola. Educ. Soc., Campinas, v. 35, nº 129, p. 1085-1114, out.-dez., 2014.

HYPOLITO, A. M. Políticas curriculares, Estado e regulação. Educ. Soc. Campinas, SP, v. 31, n. 113, p. 1337-1354, out./dez. 2010.

NOVAES, Maria Eliana. Professora primária: mestra ou tia? São Paulo: Cortez, 1984.

OLIVEIRA, D. A. Nova gestão pública e governos democrático-populares: contradições entre a busca da eficiência e a ampliação do direito à educação. Educ. Soc., Campinas, v. 36, nº 132 , p. 625-646, jul.-set., 2015.

OLIVEIRA, D. A. Política educacional e a reestruturação do trabalho docente: reflexões sobre o contexto latino- americano. Educação e Sociedade, Campinas, v. 28, n. 99, p. 355- 375, maio/ago. 2007. 
OLIVEIRA, D. A. A reestruturação do trabalho docente: precarização e flexibilização. Educ. Soc. [online]. 2004, vol.25, n.89, pp. 1127-1144. ISSN 0101-7330. doi: 10.1590/S010173302004000400003

OLIVEIRA, D. A. Regulação das políticas educacionais na América Latina e suas consequências para os trabalhadores docentes. Educação e Sociedade, vol.26, n. 92. 2005.

SANTOS, L.L.C.P. Formação de professores na cultura do desempenho. Educação \& Sociedade, Campinas, v. 25, n. 89, p. 1145-1157, set./dez. 2004.

SHIROMA, E. O.; EVANGELISTA, O. A colonização da utopia nos discursos sobre profissionalização docente. Perspectiva, Florianópolis, v. 22, n. 2, p. 525-545, 2004.

SOUSA, S. M. Z. L.; OLIVEIRA, R. P. Políticas de avaliação da educação e quase mercado no Brasil. Educ. Soc., Campinas, v. 24, n. 84, p.873-895, set.2003.

Recebido em:29/10/2017

Aceito em: 24/01/2018 